\title{
The identity of the tropical African Polichne mukonja Griffini, 1908 (Orthoptera, Tettigoniidae, Phaneropterinae)
}

\author{
Bruno Massa' \\ I Department of Agriculture and Forest Sciences, University of Palermo, Viale Scienze 13, 90128 Palermo, Italy \\ Corresponding author: Bruno Massa (bruno.massa@unipa.it)
}

Academic editor: F. Montealegre-Z | Received 30 July 2016 | Accepted 6 September 2016 | Published 3 October 2016

http://zoobank.org/8D67FF6F-1ADC-4CCE-8527-2C6267F1C61D

Citation: Massa B (2016) The identity of the tropical African Polichne mukonja Griffini, 1908 (Orthoptera, Tettigoniidae, Phaneropterinae). ZooKeys 621: 37-44. doi: 10.3897/zookeys.621.9725

\begin{abstract}
Polichne mukonja Griffini, 1908 from Cameroon was hitherto known only from the holotype preserved at the Royal Belgian Institute of Natural Sciences, Brussels. This was probably due to the fact that the genus Polichne Stål, 1874 distributed only in Australia and Papua New Guinea. In view of this distribution, the tropical African species was therefore overlooked in the African literature. The recent discovery of two specimens at the Naturhistorisches Museum, Vienna, now provides us with a better understanding of the identity of this taxon, which is related to the African genus Catoptropteryx Karsch, 1890. Polichne mukonja is here transferred to a new genus Griffinipteryx and both taxa are proposed to be included in the new tribe Catoptropterigini.
\end{abstract}

\section{Keywords}

Catoptropterigini trib. n., distribution, Griffinipteryx gen. n., taxonomy, tropical Africa

\section{Introduction}

Griffini (1908), when describing Polichne mukonja from Cameroon (Mukonje Farm), highlighted that it was the first African species from this genus. The genus Polichne Stål, 1874 was indeed previously known only from Australia and Papua New Guinea. 
However, it seemed very probable that the species described by Griffini belonged to a different genus from Polichne, but the detailed description by Griffini (1908), has been forgotten for more than a century. Curiously, Ragge $(1968,1980)$ also overlooked it, first when he listed all the African Phaneropterinae (1968) and then when revising the African Phaneropterinae with open tympana (1980).

A recent study of the material preserved at the Naturhistorisches Museum of Vienna revealed two specimens, both females (like the holotype). These were probably collected towards the end of 1800s, prior to the description of the species by Griffini (1908). These specimens possess the following characters: slender body, fore coxae armed, open tympana on both sides of fore tibiae, black stripe along the body, and very short ovipositor, similar to that of Catoptropteryx Karsch, 1890. They fit very well with the description by Griffini (1908) of Polichne mukonja. Jerome Constant (RBINS, Royal Belgian Institute of Natural Sciences, Brussels) kindly provided a photograph of the type specimen; later this was compared with the Vienna specimens and it was possible to establish that they both belonged to the species described by Griffini (1908). However, on the base of its characters, it is now possible to ascertain that the African species Polichne mukonja belongs to an entirely new genus to which its description is being presented in this work.

\section{Material and methods}

The material examined (see below) is preserved at the Naturhistorisches Museum of Vienna (NMW). This study of Polichne mukonja has been carried out on specimens belonging to genera considered within the Ephippithytae group, particularly in the shape of the pronotum, the face and ovipositor and the presence of spines on the femora. Measurements were taken using a caliper Digimax measy 2000 (precision: $0.01 \mathrm{~mm}$ ). The following measurements were taken (in $\mathrm{mm}$ ): Body length: dorsal length from the head to the apex of the abdomen, ovipositor excluded; Pronotum length: length of the pronotum along dorsal median line; Pronotum height: maximum height of the pronotum; Hind femur: length of hind femur; Tegmina: length of tegmina; Ovipositor: maximum length from the subgenital plate to the tip of the ovipositor. Photographs were taken with a Nikon Coolpix 4500 digital camera, mounted on a Wild M5 Stereomicroscope, and photos were integrated using the freeware CombineZP (Hadley 2008).

\section{Results and discussion}

Griffinipteryx gen. $\mathbf{n}$.

http://zoobank.org/BA4B0B72-6445-4E17-9D2C-841C5EA3348B

Figs 1-6

Type species. Griffinipteryx mukonja (= Polichne mukonja Griffini, 1908). 


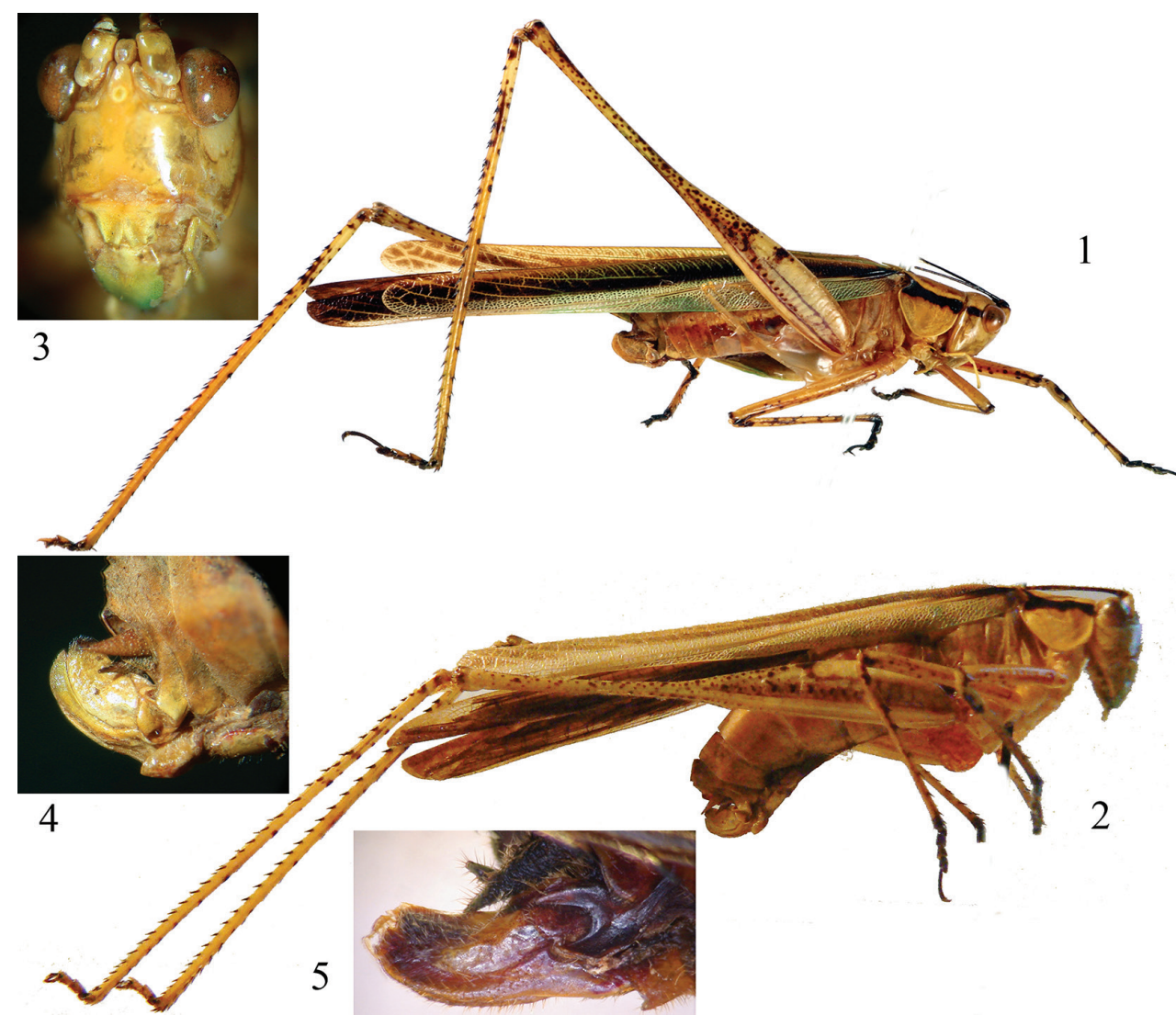

Figures I-5. I The Holotype of Polichne mukonja Griffini, 1908, now included in the new genus Griffinipteryx (photo by Jerome Constant, Royal Belgian Institute of Natural Sciences, Brussels) 2 Griffinipteryx mukonja, female from Cameroon (Naturhistorisches Museum, Vienna) 3 Face in frontal view of the same 4 Lateral view of the ovipositor of Griffinipteryx mukonja $\mathbf{5}$ Lateral view of the ovipositor of Catoptropteryx extensipes Karsch, 1896.

Diagnosis. Griffinipteryx is characterized by slender body, lateral lobes of pronotum as deep as wide, ovipositor much reduced (Figs 1-4, 6).

Description. Head and antennae: fastigium of vertex narrow and pointed, much narrower than the first antennal segment. Eyes round, prominent, face smooth without fronto-genal carinae, higher than wide.

Thorax: pronotum just longer than high, with a well-developed humeral excision, lateral lobes are as deep as wide.

Legs: long (ratio body length/length hind femur: 0.9), fore coxae armed with a fine spine, fore, mid and hind femora unarmed, fore, mid and hind tibiae with ventral and dorsal spines. Fore tibiae with anterior and posterior open tympana.

Tegmina elongated, well developed, shorter than hind wings.

Ovipositor very reduced, crenulated on upper apex. 
Etymology. Griffinipteryx (Griffini + pteryx) is dedicated to the late Achille Griffini (1870-1932), distinguished Italian entomologist, who studied many African collections of Orthoptera and described Polichne mukonja; the Greek suffix pteryx (wing) is a reminder of the genus Catoptropteryx.

Affinities. Catoptropteryx is certainly the only other African genus related to Griffinipteryx. In particular, some C. punctulata Karsch, 1890 specimens have a similar colour pattern in the pronotum (Fig. 7), even if the black stripe is absent on the lateral lobes. Catoptropteryx may have small spines at the ventral inner margin of fore, mid and hind femora, while Griffinipteryx gen. n. has unarmed fore and mid femora (in actual fact a very small spine is present at the base of the ventral inner margin of the fore and on the ventral outer margin of the mid femora). Other differences are also detectable in the shape of the lateral lobes of the pronotum. In Catoptropteryx the pronotal lobes are deeper than wide, while in Griffinipteryx gen. n. they are as deep as wide (Figs 6-7). Also the length of the hind femora is proportionally longer in Griffinipteryx gen. n. than in Catoptropteryx. However, the most important character that separates the two genera is the shape of the ovipositor. While in Catoptropteryx the ovipositor is very reduced and simplified (cf. Fig. 2 of Huxley 1970), in Griffinipteryx gen. n. it is more apically chitinous, mainly in the apical dorsal margin, where it is a somewhat crenulated. In some species of Catoptropteryx the dorsal valve may also be crenulated (Huxley 1970), but the ovipositor appears longer with slender infra- and supra-gonangulum, and less chitinous. In Griffinipteryx the ovipositor and the subgenital plate are more chitinous and infra- and supra-gonangulum are stout (compare Figs 4 and 5).

\section{Griffinipteryx mukonja (Griffini, 1908)}

Depository of the type. Cameroon, Mukonje Farm ( $q$ holotype) (RBINS, Brussels) (photograph examined by courtesy of Jerome Constant).

Material examined. Cameroon, Johann-Albrechtshöhe [near Lake Barombi, ca. $80 \mathrm{~km}$ from Mukonje], Rhode (2 + ) (coll. Brunner von Wattenwyl, NMW, Vienna).

General habitus and colour. Yellow-brownish, a black stripe from behind the eye on the head through the lateral lobes of the pronotum and gradually broadening along the tegmina. Abdomen yellow with some brown spots; legs yellow with many black dots; tympanum with a black anterior margin; fore and mid tarsi black, hind tarsi yellow with a black base.

Description. Female. Fastigium of vertex sulcate above; face smooth without fronto-genal carinae, higher than wide. Pronotum without lateral carinae, surface shiny, with a well-developed humeral excision on the lateral lobes. Anterior margin of pronotum straight, posterior margin gently rounded, pronotum lobes rounded on posterior margins. Fore coxae armed with a fine spine; a very small spine is present at the base of the ventral inner margin of fore and of ventral outer margin of the mid femora, hind femora unarmed; fore tibiae with 3 black spines on ventral inner margin, 3 spines +1 apical spur on ventral outer margin, 1 spine dorsal on fore tibia above tympanum +1 apical spur; 


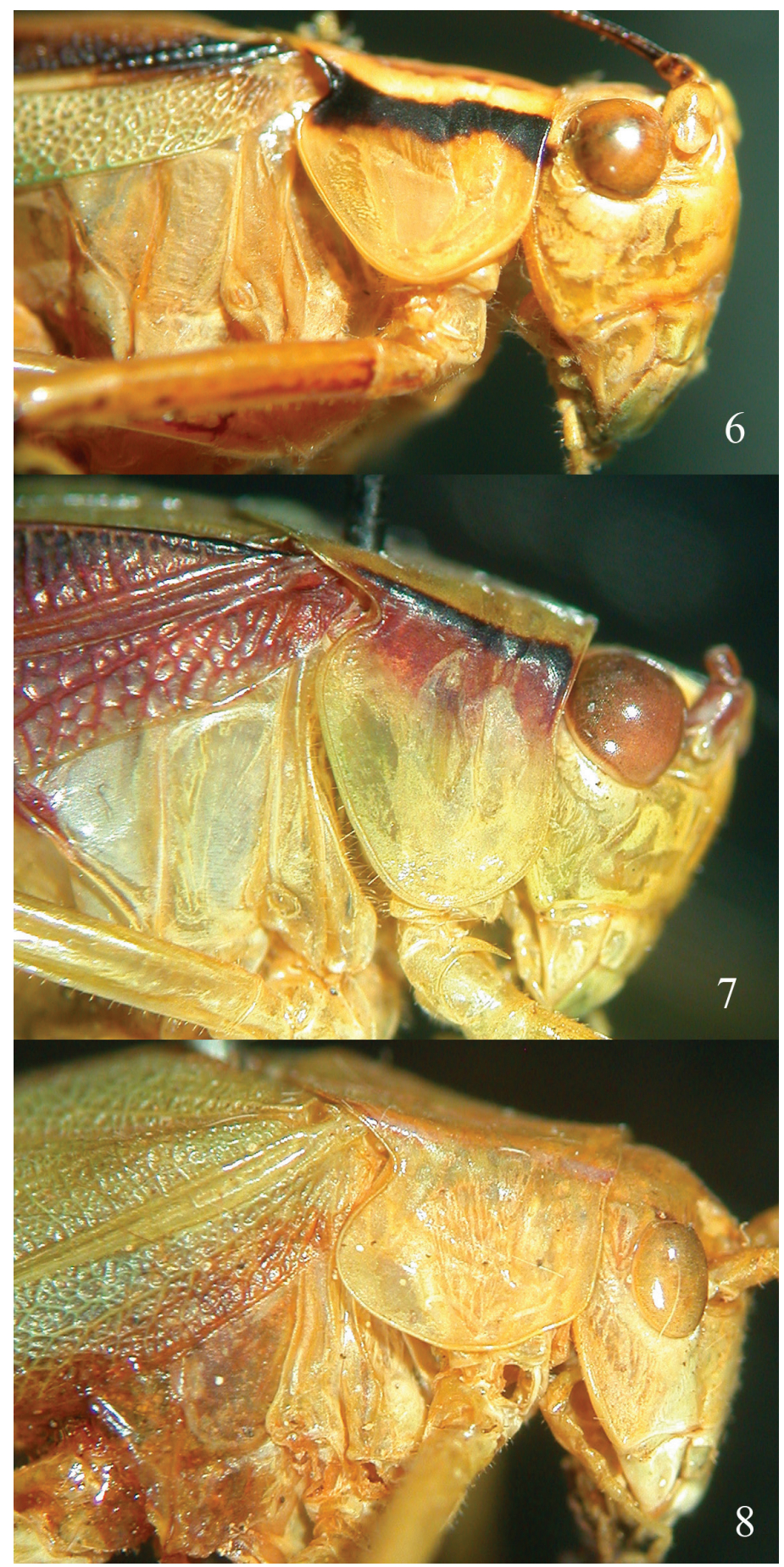

Figures 6-8. 6 Lateral view of head and pronotum of Griffinipteryx mukonja from Cameroon 7 Lateral view of head and pronotum of Catoptropteryx punctulata Karsch, 18908 Lateral view of head and pronotum of Polichne parvicauda (Stål, 1861), type species of the genus Polichne. 
Table I. Measurements of two females of Griffinipteryx mukonja (Griffini, 1908); measurements in brackets recorded by Griffini (1908).

\begin{tabular}{l|c}
\hline Body length & $22.7-24.5(20)$ \\
\hline Pronotum length & $4.8-4.9(4.7)$ \\
\hline Pronotum height & $4.3-4.4$ \\
\hline Length of hind femur & $25.8-26.0(26.5)$ \\
\hline Tegmina length & $27.5-29.2(27)$ \\
\hline Tegmina width & $3.4(3.7)$ \\
\hline Length of hind wing & $31.8-33.5(31.3)$ \\
\hline Ovipositor & $3.2-3.3(2.4)$ \\
\hline
\end{tabular}

mid tibiae with 4-5 black spines on ventral inner margin +1 apical spur, 6 black spines ventral on outer margin +1 apical spur, 1 dorsal inner black spine +1 apical spur; hind tibiae with 9-10 black spines ventral on both margins +2 apical spurs on each side; dorsal margins of hind tibiae with many black and yellow black tipped spines +1 apical spur on each side. Abdomen: styli pointed, ovipositor very short with crenulated dorsal apex. Subgenital plate triangular and short, as long as wide, apically rounded.

Male: unknown.

Measurements. See Table 1.

\section{Catoptropterigini trib. $\mathbf{n}$.}

http://zoobank.org/7A9E56A9-2D0C-41C7-88F1-A6E836D84276

\section{Type genus. Catoptropteryx Karsch, 1890.}

Currently the genus Catoptropteryx Karsch, 1890 belongs to the species group Ephippithytae Brunner von Wattenwyl, 1878, together with another eleven genera found in Australia and Papua New Guinea. This group of species is very heterogeneous and probably the sole character that brings them together is the reduction of the female ovipositor, even if its structure is much different in some of them. To include the African genus Catoptropteryx in this heterogeneous group of Australasian genera seems like a biogeographical nonsense. As a first step, the comparison of the African species $P$. mukonja described by Griffini (1908) was carried out on the type species Polichne parvicauda (Stål, 1861) ( from Australia, NMW), originally described as Phaneroptera, and the following differences were noticed (Fig. 8): presence of fronto-genal carinae, eyes oval, fastigium sulcate, short ovipositor, but not as reduced as in mukonja, pronotum with a deep humeral excision, just longer than high, of different shape compared to mukonja. Then, the type species of the genus Ephippitytha $a^{1}$ Serville, 1838 [E. trigintiduoguttata (Serville, 1838)] was examined (6 specimens of both sexes from Australia, NMW). It has clear fronto-genal carinae, large spines on both margins of the hind femora, one spine on both apices of fore, mid and hind femur knees, pronotum centrally narrowed, similar to

\footnotetext{
Ephippithyta Brunner von Wattenwyl, 1878 is a synonym.
} 
a saddle, ovipositor much reduced, but slender and pointed. In addition, the ovipositor of the other nine genera in the Ephippithytae group is heterogeneous even if reduced, eyes may be round or elongate and fronto-genal carinae may be both present or absent.

When the first species of Catoptropteryx were discovered, they were described within the Australian genus Caedicia Stål, 1874 (e.g.: afra: Karsch 1888; apicalis: Bolívar 1893), also included in the Ephippithytae group. Thus, when Karsch (1890) erected for them the genus Catoptropteryx it was considered logical at the time to include this genus in the Ephippithytae group, erected by Brunner von Wattenwyl in 1878. However, also Caedicia is evidently different from Catoptropteryx (examined 60 of the type species of the genus, Caedicia pictipes Stål, 1874, and a few specimens of the other six species, C. marginata Brunner von Wattenwyl, 1878, C. concisa Brunner von Wattenwyl, 1878, C. septentrionalis Brunner von Wattenwyl, 1878, C. simplex (Walker, 1869), C. inermis Brunner von Wattenwyl, 1878, and C. scalaris Brunner von Wattenwyl, 1878, all from Australia, NMW, coll. Brunner von Wattenwyl). The characteristics of this genus are: eyes round, small spines on femur knees, presence of spines on lower margins of femora, fronto-genal carinae. While these characters are evident in the type species, they are not always present in other species (e.g.: eyes may be oval, spines in femur knees may be absent). Overall, it may be confirmed that the Ephippithytae group is very heterogeneous and therefore it cannot be considered as a tribe.

Presently, in the light of the revision of the genus Catoptropteryx by Huxley (1970) and the discovery of the identity of the African Polichne mukonja Griffini, 1908 (now Griffinipteryx mukonja), the new tribe Catoptropterigini seems a logical taxonomical consequence.

Characters of the tribe are the following. Fastigium narrower than first antennal segment, furrowed, face smooth without fronto-genal carinae, eyes round, very small spines or unarmed lower margins of fore and mid femora, hind femora with few small spines or unarmed, tegmina longer than wings, ovipositor very reduced.

\section{Concluding remarks}

In 1908 the Italian entomologist Achille Griffini described the katydid Polichne mukonja from Cameroon. Incomprehensibly he described this taxon within the Australian genus Polichne, which does not show any morphological affinities with it. Only the holotype was known (specimen preserved at the Royal Belgian Institute of Natural Sciences, Brussels), and later on this taxon was no longer cited. When an opportunity arose to study the African material preserved in the Naturhistorisches Museum of Vienna, during a Synthesys project, two other specimens of this taxon were discovered and it was possible to understand its identity. Polichne mukonja resulted as belonging to a newly established genus (Griffinipteryx) and is rather related to the tropical African genus Catoptropteryx, for which the new tribe Catoptropterigini is here proposed. This present work continues to demonstrate that Natural History museums preserve interesting treasures that are still waiting to be discovered. 


\section{Acknowledgements}

This research received support from the Synthesys Project, which is financed by the European Community Research Infrastructure Action under the FP7 "Capacities" Programme at the Naturhistorisches Museum, Vienna (2016: AT-TAF-5324), the Museo Nacional de Ciencias Naturales, Madrid (CSIC) (2013: ES-TAF-2438) and the Museum für Naturkunde, Berlin (2014: DE-TAF-4109). I am especially indebted to Jerome Constant (Royal Belgian Institute of Natural Sciences, Brussels), Suzanne Randolf and Harald Bruckner (Naturhistorisches Museum, Vienna), Mercedes Paris (Museo Nacional de Ciencias Naturales, Madrid), Michael Ohl (Museum für Naturkunde, Berlin), Roberto Poggi, Maria Luisa Tavano and Giuliano Doria (Museo Civico di Storia Naturale 'G. Doria', Genoa), who all facilitated the study of specimens preserved in their museums. I am also very much indebted to Philippe Moretto, who kindly made available the material collected during 2012, 2013, 2014 and 2015 from central and west African countries. I am also grateful to Claudia Hemp and Klaus-Gerhard Heller for their improvements to a first version of the manuscript, and to John J. Borg for revising the English.

\section{References}

Bolívar I (1893) Voyage de M. Ch. Alluaud dans le territoire d'Assinie (Afrique occidentale) en juillet et aout 1886. Orthoptères. Annales de la Société Entomologique de France 62: 169-185. http://www.biodiversitylibrary.org/item/34137\#page/175/mode/1up.

Brunner von Wattenwyl C (1878) Monographie der Phaneropteriden. Vienna, 401 pp. http:// www.biodiversitylibrary.org/item/37136

Griffini A (1908) Phasgonuridae africane del R. Museo di Storia Naturale in Bruxelles. 6. Phaneropteridae pars 2a (reliquae species omnes). Mémoires de la Societé entomologique belgique 15: 201-226. http://www.biodiversitylibrary.org/item/41740\#page/215/mode/1up

Hadley A (2008) Combine Z. http://www.hadleyweb.pwp.blueyonder.co.uk [February 2009]

Huxley J (1970) A revision of the genus Catoptropteryx Karsch (Orthoptera: Tettigoniidae).

Bulletin British Museum natural History (Entomology) 24: 129-170. http://www.archive.org/details/bulletinofbritis24entolond

Karsch F (1889) Orthopterologische Beiträge III. Berliner Entomologische Zeitschrift 32(1888): 415-464. http://www.biodiversitylibrary.org/item/34458\#page/475/mode/1up

Karsch F (1890) Verzeichnis der von Herrn Dr. Paul Preuss auf der Barombi-Station in Deutsch-Westafrika 1890 gesammelten Locustodeen aus den Familien der Phaneropteriden, Mekonemiden und Gryllakriden. Entomologische Nachrichten 16(23): 353-369. http://www.biodiversitylibrary.org/item/81935\#page/367/mode/1 up

Ragge DR (1968b) An index-catalogue of African Phaneropterinae (Orthoptera: Tettigoniidae). Bulletin British Museum (Natural History) Entomology 22: 73-108. https://archive. org/details/bulletinofbritis22entolond

Ragge DR (1980) A review of the African Phaneropterinae with open tympana (Orthoptera: Tettigoniidae). Bulletin British Museum (Natural History) Entomology 40: 1-192. http:// www.archive.org/details/bulletinofbritis40entolond 